\title{
What is new at the data front?
}

\author{
Stefanie Hellweg ${ }^{1,2} \cdot$ Rainer $\mathrm{Zah}^{3}$
}

Received: 18 July 2015 / Accepted: 21 April 2016/Published online: 17 May 2016

(C) Springer-Verlag Berlin Heidelberg 2016

Every LCA needs data, lots of data and good data. Without inventory databases we would probably spend years for an LCA study — or we would not do LCA at all. New and more far-reaching applications of LCA, like EPD tools, company LCA, or national footprints increase the demand for data, while new developments in impact assessment, like water footprinting or natural capital valuation, also require advancements in inventory models. Open questions include: How can we cope with additional data challenges that are imposed by the increasing globalization of value chains? How do we intend to apply new regionalized impact assessment methods if the corresponding inventory data is not available? What do we do if the ISO norms require a sensitivity analysis of allocation approaches or if the allocation approach that was agreed on in a harmonization activity (e.g. Product Environmental Footprint, PEF) is not followed by the background inventory databases? What chances does "big data" offer for LCA, e.g. in terms of behavioural data for the use phase? These and further questions highlight that inventory models and databases are a dynamic field of research, where continuous innovation is key. This special issue describes how ecoinvent as a leading data initiative in LCA is addressing these challenges to cope with the growing demand for environmental services.

Stefanie Hellweg is the president of the ecoinvent Association and Rainer $\mathrm{Zah}$ is a former board member of the ecoinvent Association

Stefanie Hellweg

hellweg@ifu.baug.ethz.ch

1 Ecoinvent Association, 8005 Zurich, Switzerland

2 Institute of Environmental Engineering, ETH Zurich, 8093 Zurich, Switzerland

3 Quantis, Reitergasse 11, 8004 Zurich, Switzerland

\section{What new data does ecoinvent version 3 deliver?}

Version $3(\mathrm{v} 3)$ provides more data and, especially, data with a larger geographic coverage. The papers of Wernet et al. (2016) and Meinshausen et al. (2015) describe the methodological changes that were made to be able to accommodate more international data, including the new structure of activity and market datasets. The two papers by Treyer and Bauer (2015a, b) show how the electricity sector was expanded in geographical coverage, on the level of technological and market mix representation, to 71 regions and 50 countries. The paper by Steubing et al. (2016) shows the consequences of this geographical expansion: both in $\mathrm{v} 2$ and in v3 electricity contributed, on average, approximately $40 \%$ to the climate change impact of global datasets. However, as v2 mainly contained European supply chains, more than $90 \%$ of the electricity related emissions from global production datasets were assumed to occur in Europe. In contrast, in v3, the global production volume is modelled for every activity either by one global activity or several local activities. Therefore, emissions related to the electricity demand of global production datasets are now also globally distributed, which increases the geographical accuracy of the supply chains. The paper of Lesage and Samson (2015) gives an example of a concerted action to feed in a large amount of regional LCI data, using the example of Quebec, and the paper by Suh et al. (2015) discusses the compatibility of other regional databases to ecoinvent. These are just some examples showing the initial steps towards an increasingly internationalized ecoinvent. ecoinvent v3.2 contains even more geographical coverage. In particular, electricity generation has been further extended, with more than $90 \%$ worldwide coverage. A new project with regional data collection in Brazil, India, and South Africa has been set up and will provide data from transitional regions in the coming years. The papers in this special issue thus 
illustrate the start of this strategic development of increasing internationalization of data, urgently needed in view of the efforts of LCA to assess global value chains and of increasing LCA use also in the Southern hemisphere.

Furthermore, in ecoinvent v3, various sector data has been improved and updated (see paper 1 by Treyer and Bauer (2015a) for the electricity sector and Simons (2015) for the personal transport sector) and new data has been added (see paper by Del Duce et al. (2015) for electric vehicle transport and paper 2 by Treyer and Bauer (2015b) for the geographical expansion of electricity market datasets).

Research on uncertainty has also advanced (see papers by Muller et al. (2015) and Ciroth et al. (2015)). All these developments highlight the efforts that have been made to maintain the cutting-edge status of inventory.

\section{The new system models}

Ecoinvent now displays enlarged flexibility due to its new system models (see paper by Wernet et al. (2016)). The cutoff system model (recycled content allocation approach) corresponds to the model that was used in v1 and v2 and is so far the most elaborated and quality-controlled system model. For this reason and because it provides continuity, it is the standard system model for most users. In addition, v3 features two new system models, the allocation at the point of substitution (APOS) system model and the consequential system model. Concerning the latter, this is the first large-scale consequential database providing background data, and even if not all technologies are already modelled perfectly with regard to their marginality, it is a start. APOS serves as allocation alternative to the cut-off model for attributional LCA. All system models serve well for sensitivity analysis of allocation approaches (as recommended by ISO 14044). Thus, users may apply the traditional cut-off system model for their base analysis, for instance, and then apply the other two system models in a sensitivity analysis to check if the results change according to the allocation approach chosen. Since allocation is set to be a subjective and highly debated choice in the future, providing these different system models and making the effect of allocation choices transparent is a large value added to any LCA study. Still, the benefits arising from the availability of three system models are not as far-reaching as those arising as a result of the flexibility offered by the new data structure. The data is no longer stored as one static, interlinked database, but instead as unlinked unit processes, separated from the linking according to different system models (see paper by Wernet et al. (2016)). This structure creates more flexibility, since it will allow for fairly easy designing of tailored system models in the future. It would be of use, for instance, if e.g. a political or industry initiative chooses to go for a new allocation approach, which is not practised by any database at the moment; or if sector-specific databases with specific needs are demanded, appropriate models can be created with limited effort. The new structure hence allows ecoinvent to respond to future developments with greater ease. In the same way that the internationalization of data might not be entirely evident at the moment, the user may currently only see the tip of the iceberg when it comes to the new structure. However, the "invisible" underlying changes are preparing ecoinvent for future changes and will become obvious in the long-term.

\section{Improving and extending the elementary flows}

Several development initiatives were dedicated to specific sectors or special elementary flows. The World Water Database from Quantis has been integrated in ecoinvent v3 (see paper by Pfister et al. (2015)), making it possible to model a water inventory along the full value chain. This facilitates the calculation of a regionalized water footprint according to the ISO 14'046 standard. The modelling of nitrogen emissions and land use implications on climate change is another example of innovations (see paper by Nemecek et al. (2015)).

\section{The evolution of ecoinvent}

Ecoinvent has supplied inventory data to thousands of users for almost two decades (counting in the early versions in the 1990s (Frischknecht et al. 1994)). It was a pioneer project in many aspects, in terms of earliness and data volume, but particularly in terms of harmonization of data, consistency and transparency. These core strengths constitute the key goals of ecoinvent. The unit process approach and transparent documentation are indispensable for scientific studies, which by definition must be reproducible. For practitioners, transparency adds to credibility. While there are some practical changes in v3, e.g. a move of data documentation from separate reports to documentation in the datasets, the commitment to transparency, harmonized quality control and consistency is not compromised by the changes that are described in this special issue.

Putting together this special issue has been a somewhat lengthy process, as can be seen from the publication dates of the individual papers. Version 3 of ecoinvent was very ambitious. Many of the changes made from version 2 to 3 were of methodological nature, to prepare the database for future developments. Not all of these changes are visible to the user and they add some complexity. Moreover, initially there were problems regarding the conversion of $\mathrm{v} 2$ data to $\mathrm{v} 3$ data, leading to the reluctance of many users to adopt v3, especially since there were many changes at a time, as well as some "child diseases". With v3.1, the "cut-off system model" was re-introduced and several simplifications were made to 
warrant continuity and user-friendliness. With v3.2 further improvements for applicability were made, e.g. summarizing electricity inventory flows in in market groups to allow for a better system overview. The publication of this special issue is therefore timely, as now v3 is at a point where all important developments have been implemented to the full in most LCA software systems, with many practitioners relying on ecoinvent $\mathrm{v} 3$ as their principal data source.

\section{What does the future bring?}

After a period of methodological development, data development is now the primary focus again. In addition to new and geographically more representative data, maintenance is now a primary challenge. While every release also contained many data updates, some data would benefit from a refresh. The degree of updates is, on purpose, visible to all users, by indicating the age of data on a unit process level to give an idea of the reliability of each dataset, meaning that obsolete datasets are not hidden in aggregated datasets. Continuously updating the database is, therefore, a crucial task for the coming versions. ecoinvent intends to act flexibly at the forefront of LCA developments and to gradually adapt to future needs, warranting continuity for long-term users.

Many people have contributed to this special issue as authors, and even more people have supported the database otherwise (see www.ecoinvent.org). ecoinvent has grown from a national to an international initiative to provide the LCA community with good, up-to-date, consistent and transparent data or, as ecoinvent puts it in its vision "to help people all around the world do high quality environmental assessments more easily". We want to thank everyone who has participated in this endeavour and invite further people to join this initiative, for example by supplying datasets or by giving feedback about what should be improved, or by taking on active roles, such as becoming an ecoinvent editor.

Acknowledgments We thank Bernhard Steubing and Stephan Pfister for commenting an earlier draft of this editorial and Catherine Raptis for language proofreading.

\section{References}

Ciroth A, Muller S, Weidema B, Lesage P (2015) Empirically based uncertainty factors for the pedigree matrix in ecoinvent. Int $\mathrm{J}$ Life Cycle Assess. doi:10.1007/s11367-013-0670-5 (this issue)

Del Duce A, Gauch M, Althaus HJ (2015) Electric passenger car transport and passenger car datasets in ecoinvent version 3. Int $\mathrm{J}$ Life Cycle Assess. doi:10.1007/s11367-014-0792-4 (this issue)

Frischknecht R, Hofstetter P, Knoepfel I (1994) Ökoinventare für Energiesysteme - Grundlagen für den ökologischen Vergleich von Energiesystemen und den Einbezug von Energiesystemen. ETH Zürich 1 PSI Villigen

Lesage P, Samson R (2015) The Quebec life cycle inventory database project - using the ecoinvent database to generate, review, integrate and host regional LCI data. Int J Life Cycle Assess. doi:10.1007/ s11367-013-0593-1 (this issue)

Meinshausen I, Müller-Beilschmidt P, Viere T (2015) The EcoSpold 2 format — why a new format? Int J Life Cycle Assess. doi:10.1007/ s11367-014-0789-z (this issue)

Muller S, Lesage P, Ciroth A, Mutel C, Weidema BP, Samson S (2015) The application of the pedigree approach to the distributions foreseen in ecoinvent v3. Int J Life Cycle Assess. doi:10.1007/s11367014-0759-5 (this issue)

Nemecek TJ, Schnetzer J, Reinhard J (2015) Updated and harmonised greenhouse gas emissions for crop. Int J Life Cycle Assess. doi:10. 1007/s11367-014-0712-7 (this issue)

Pfister S, Vionnet S, Levova L, Humbert S (2015) Ecoinvent 3: assessing water use in LCA and facilitating water footprinting. Int J Life Cycle Assess. doi:10.1007/s11367-015-0937-0 (this issue)

Simons A (2015) Road transport: new life cycle inventories for fossil fuelled passenger cars and non-exhaust emissions in ecoinvent $\mathrm{v} 3$. Int J Life Cycle Assess. doi:10.1007/s11367-013-0642-9 (this issue)

Steubing B, Wernet G, Reinhard J, Bauer C, Moreno E (2016) The ecoinvent database version 3 (part II): analyzing LCA results and comparison to version 2. Int J Life Cycle Assess. doi:10.1007/ s11367-016-1088-7 (this issue)

Suh S, Leighton M, Tomar S, Chen C (2015) Interoperability between ecoinvent ver. 3 and US LCI database: a case study. Int J Life Cycle Assess. doi:10.1007/s11367-013-0592-2 (this issue)

Treyer K, Bauer C (2015a) Life Cycle Inventories of electricity generation and power supply in version 3 of the ecoinvent database - part I: electricity generation. Int J Life Cycle Assess. doi:10.1007/ s11367-013-0665-2 (this issue)

Treyer K, Bauer C (2015b) Life Cycle Inventories of electricity generation and power supply in version 3 of the ecoinvent database - part II: electricity markets. Int J Life Cycle Assess. doi:10.1007/s11367013-0694-x (this issue)

Wernet G, Bauer C, Steubing B, Reinhdard J, Moreno Ruiz E, Bo W (2016) The ecoinvent database version 3 (part I): overview and methodology. Int J Life Cycle Assess. doi:10.1007/s11367-016-1087-8 (this issue) 